\title{
In vitro fibroblasts viability and migration stimulation of Acalypha indica: an insight on wound healing activity
}

\author{
Ammar Mahmoud Ibrahim ${ }^{1 *}$ (D), Mariani Abdul Hamid ${ }^{2}$, Rama Ali Althiab ${ }^{1}$, Amir Husni Mohd Shariff ${ }^{1}$ and \\ Razauden Mohamed Zulkifii ${ }^{*}$
}

\begin{abstract}
Background: The current study investigates the antioxidant activity of Acalypha indica aerial parts and root ethanolic extracts and explore whether these extracts will stimulate fibroblasts viability and ability to migrate.

Results: Aerial parts extract exhibited higher DPPH scavenging activity compared to root extract with $\mathrm{IC}_{50}$ of $62 \mu \mathrm{g} /$ $\mathrm{mL}$ and $206 \mu \mathrm{g} / \mathrm{mL}$, respectively. Both aerial parts and root extracts showed low cytotoxicity towards fibroblasts with $753 \mathrm{\mu g} / \mathrm{mL} \mathrm{LD}_{50}$ for aerial parts and undetected $\mathrm{LD}_{50}$ for root extract. Additionally, aerial parts extract significantly induces fibroblasts proliferation up to $134 \%$. Wound closure investigation showed a significant closure percentage for aerial parts compared to untreated control with $75 \%$ at $1 \mu \mathrm{g} / \mathrm{mL}$ and high closure percentage with $70 \%$ at $0.1 \mu \mathrm{g} / \mathrm{mL}$ for root extract compared to only $59 \%$ closure percentage for untreated control after $48 \mathrm{~h}$ of the study.

Conclusions: This study provided evidence for $A$. indica to have great wound healing potential. The finding builds the scientific background in future to utilise the high antioxidant activity of $A$. indica and its ability to stimulate fibroblasts migration and proliferation for further applications.
\end{abstract}

Keywords: In vitro, Acalypha indica, Wound healing, Cytotoxicity, Antioxidant

\section{Background}

Ancient civilisations exploited plant-based treatments as the primary source for remedies to cure diseases [1]. Through decades, those traditional remedies have proved efficacy even without any scientific justification. New researches on traditional medicines are now revealing rational shreds of evidence on efficacy, safety, and therapeutic mechanisms of these remedies and proposing safe dosing, suitable formulations, and feasible routes of administration [2].

Winter and Scales were the first to study the healing process in the 1960s [3]. Since then, science has been revealing much more about systemic factors affecting

\footnotetext{
*Correspondence: ammaibr@gmail.com; razauden@fbb.utm.my

${ }^{1}$ Department of Biosciences, Faculty of Science, Universiti Teknologi

Malaysia, 81310 Skudai, Johor, Malaysia

Full list of author information is available at the end of the article
}

wound healing on biochemical, cellular, and molecular levels. Our current understanding of the healing process associates it with different biological activities. To consider herbal extract as a wound healing therapeutic, it should have a favorable effect on at least two of the following mechanisms: effect on fibroblast or keratinocyte cells; formation of collagen; and anti-inflammatory, antimicrobial, or antioxidant activity [4].

Acalypha indica (Family: Euphorbiaceae) is a small annual shrub found in tropical areas and throughout Polynesia. Over the centuries, traditional healers used $A$. indica for wound healing management [5]. Studies on $A$. indica identified abundant varieties of second metabolites such as glycosides, triterpenes, amides, tannins, cyanogenic glucoside acalyphin, including antioxidant entities such as Acalyphamide (flavonoid) and Acalyphine (alkaloid) [6-9]. Many in vivo studies on herb extracts 
proved its wound healing properties [10-14]. The findings attribute its wound healing property to different mechanisms, including anti-inflammatory activity [8, $15,16]$, antimicrobial activity [12, 17], analgesic effects [16], and antioxidant activity [6, 11, 14, 16]. However, there is still a need for more investigations on the safety and efficacy of this herb on live cells: like fibroblasts and keratinocytes, which have vital roles in the healing process.

When wounding occurs, it triggers fibroblasts remodelling as myofibroblasts (ultrastructural morphology fibroblasts) that are crucial entities in the proliferative phase of the healing process. Activated myofibroblasts interact with epithelial cells to develop the granulation tissue; proliferate and migrate allowing granulation tissue to contract and maturate; stimulate the production of growth factors, collagen, and extracellular matrix proteins [18].

This study aims to validate the antioxidant activity of Acalypha indica aerial parts and root ethanolic extracts and explore whether these extracts will stimulate fibroblasts viability and ability to migrate. Further awareness of A. indica impact on fibroblasts will grant us more insight into triggered healing mechanisms. Moreover,
Bovine Serum (FBS), Trypan blue, MTT (3-(4,5-dimethylthiazol-2-yl)-2,5-diphenyltetrazolium bromide), PBS (Phosphate Buffered Saline) (Sigma-Aldrich). ABS (Bovine Serum Albumin) (Vivantis) Pen Strep (Penicillin and streptomycin) (Gibco). Animal tissue culture lab in the Faculty of Sciences, Department of Bioscience in the corresponding university provided the Human Skin Fibroblast cell line (HSF 1189).

\section{Antioxidant DPPH free radical-scavenging activity}

We evaluated the antioxidant activity based on the scavenging activity of the aerial parts and root ethanolic extracts on DPPH $[20,21]$. Using methanol as solvent, we prepared $0.5 \mathrm{mg} / \mathrm{mL}$ ascorbic acid as standard and $(0.04 \%$ $\mathrm{w} / \mathrm{v})$ DPPH as a stock solution. DPPH scavenging activity was studied on concentration gradient of the extracts $(500 \mu \mathrm{g} / \mathrm{mL}, 250 \mu \mathrm{g} / \mathrm{mL}, 125 \mu \mathrm{g} / \mathrm{mL}, 62.5 \mu \mathrm{g} / \mathrm{mL}, 31.25 \mu \mathrm{g} /$ $\mathrm{mL}, 15.63 \mu \mathrm{g} / \mathrm{mL}$ and $7.81 \mu \mathrm{g} / \mathrm{mL}$ ). DPPH solution in methanol was used as a control, and pure methanol was used as blank. After incubation for $30 \mathrm{~min}$ at room temperature in the dark, the absorbance was taken at $517 \mathrm{~nm}$, and the antioxidant activity was expressed as $\mathrm{IC}_{50}(\mu \mathrm{g} / \mathrm{mL})$. The ability to scavenge the DPPH radicals was calculated using the following equation:

$$
\% \text { Radical scavenging }=\left\{\frac{[\text { Absorbance of control }-(\text { Absorbance of sample }- \text { Absorbance blank })]}{\text { Absorbance of control }}\right\} \times 100
$$

validating its efficiency and safety in vitro on fibroblasts will push research forward to explore $A$. indica's modes of action on live cells avoiding the ethical and economical hindrances of the in vivo studies $[4,19]$.

\section{Methods}

\section{Plant material and preparation of the extract}

In the present study, we examined two extracts of Acalypha indica: aerial parts and root extracts. Acalypha indica was planted at the School of Biomedical Engineering and Health Sciences at the corresponding university. The whole fresh plants were washed then dried at room temperature for seven days. Dry plants were then separated into aerial parts and roots. Each of the two partitions was chopped into small pieces and extracted for $24 \mathrm{~h}$ with $30 \%$ ethanol using a Soxhlet extractor. The solvent containing the extracted compounds was then concentrated using a rotary evaporator before freeze-drying the extracts for $48 \mathrm{~h}$.

\section{Chemicals}

Ethanol (96\%), Methanol, DMSO (Dimethyl Sulfoxide) (Merck). DPPH (2,2-diphenyl-1-picrylhydrazyl), L-ascorbic acid, Dulbecco's Modified Eagle's Medium (DMEM), Fetal
The assay was performed in triplicates, and the results were averaged. A dose-response curve was plotted with the percentage of inhibition against the concentration of crude extracts on a log scale. The $\mathrm{IC}_{50}$ value was then obtained from the graph.

\section{Cell viability (MTT assay)}

The cell viability effect of $A$. indica aerial parts and root ethanolic extracts on fibroblasts was carried out using MTT assay $[22,23]$. Human skin fibroblast cells (HSF 1189) were seeded in a 96-well plate at a density of $2 \mathrm{X}$ $10^{5}$ cells/well and supplemented with DMEM (containing $10 \% \mathrm{FBS}$ and $1 \%$ pen strep). After incubation for $24 \mathrm{~h}$ at $37{ }^{\circ} \mathrm{C}$ in a humidified $5 \% \mathrm{CO}_{2}$ atmosphere, we treated-80\% confluence-cells with concentration gradient of the extracts $(1000 \mu \mathrm{g} / \mathrm{mL}, 100 \mu \mathrm{g} / \mathrm{mL}, 10 \mu \mathrm{g} / \mathrm{mL}, 1 \mu \mathrm{g} /$ $\mathrm{mL}$, and $0.1 \mu \mathrm{g} / \mathrm{mL}$ ) dissolved in DMSO and left one well untreated: DMEM only. After treating the cells, we incubated them again for $24 \mathrm{~h}$. Then, we added MTT $10 \%$ to each well, and the cells were further incubated for $4 \mathrm{~h}$. After that, we removed the media and added DMSO to dissolve the formed formazan. The absorbance was measured at $575 \mathrm{~nm}$ and $655 \mathrm{~nm}$. The absorbance of formazan in untreated cells was considered as $100 \%$ proliferation or 
viability. Cell viability percentage of the samples was calculated according to the equation:

$$
\% \text { Cell viability }=\left\{\frac{\text { Absorbance of Treated cells }}{\text { Absorbance of Untreated cells }}\right\} \times 100
$$

The assay was performed in nine replicates, and the results were averaged. A dose-response curve was plotted with the viability percentage against the concentration of crude extracts on a log scale.

\section{Wound scratch assay}

In vitro wound healing activity of $A$. indica aerial parts and root, ethanolic extracts were determined by using scratch assay [22, 24, 25]. Fibroblasts were seeded in a 6-well plate at a density of $3 \times 10^{5}$ cells/well and incubated for $24 \mathrm{~h}$ to get $80 \%$ of cell confluence. We then made an artificial wound using $200 \mu \mathrm{L}$ pipette tips. The treatment was then done by applying five different concentrations $(1000 \mu \mathrm{g} / \mathrm{mL}, 100 \mu \mathrm{g} / \mathrm{mL}, 10 \mu \mathrm{g} / \mathrm{mL}, 1 \mu \mathrm{g} /$ $\mathrm{mL}$ and $0.1 \mu \mathrm{g} / \mathrm{mL}$ ) and one untreated well, which only contain growth medium (DMEM). The wound area was monitored under an inverted microscope for up to $48 \mathrm{~h}$ to observe fibroblasts migration. Images of the wound area were captured using an optical microscope (at $4 \times$ magnification) to determine the percentage of the wound area. Duplicate wells were used per condition, and two fields per well were captured at each time point. Image J $1.48 \mathrm{v}$ software was used to analyse the images and calculate the wound area.

$$
\% \text { Wound closure }=\left\{\frac{\text { Average scratch area }(0 \mathrm{~h})-\text { Average scratch area }(48 \mathrm{~h})}{\text { Average scratch area }(0 \mathrm{~h})}\right\} \times 100
$$

Table $1 I C_{50}$ values of the extracts as determined by DPPH assay

\begin{tabular}{ll}
\hline & $\mathbf{I C}_{\mathbf{5 0}}(\boldsymbol{\mu \mathbf { g } / \mathbf { m L } )}$ \\
\hline Aerial parts & 62 \\
Root & 206 \\
Ascorbic acid & 1.9
\end{tabular}

$\mathrm{IC}_{50}$ values of the free radicals scavenging activities of extracts along with ascorbic acid as standard $(n=3)$

\section{Statistical analysis}

The statistical evaluation was studied by using Microsoft Excel 2010 and IBM SPSS Statistics version 20. The normality test was completed at a 0.95 confidence level, and the data were considered normally distributed when $p>0.05$. One-way analysis of variance (ANOVA) and Kruskal-Wallis tests for parametric and non-parametric data were respectively used to determine the mean differences between the variables. The differences were considered statistically significant when $p<0.05$. For the Post-Hoc test of ANOVA, Dunnett $t$ was used for multiple data comparisons with homogeneous variances, whereas Games-Howell was used for data with non-homogeneous variances. Mann-Whitney test was used to study the differences in non-parametric data.

\section{Results}

Antioxidant DPPH free radical-scavenging activity

Figure 1 shows that at high concentration $(500 \mu \mathrm{g} /$ $\mathrm{mL}$ ), aerial parts extract had no significant difference

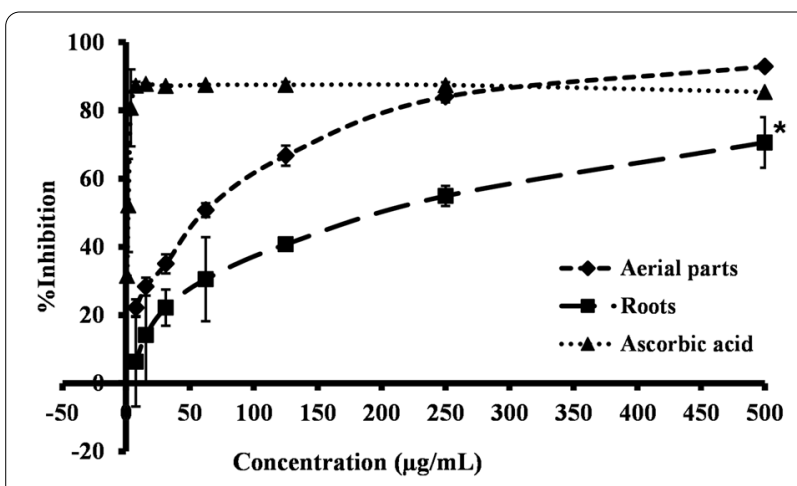

Fig. 1 Scavenging effect of DPPH. Values are expressed as mean $\mathrm{DPPH}$ inhibition\% $\pm \mathrm{SD}(n=3)$. Statistical analysis was carried out using one-way ANOVA followed by $t$ test. *Statistically significant between arial parts/root extracts in each concentration vs. ascorbic acid at ${ }^{*} p<0.05$

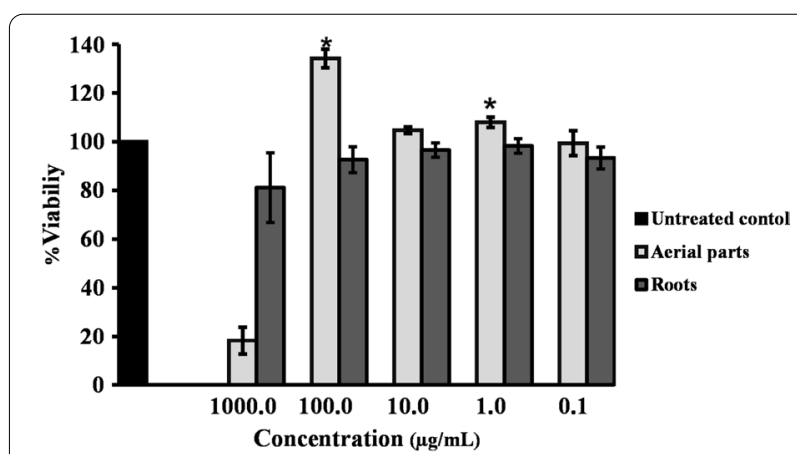

Fig. $2 \%$ Viability of HSF 1189 with different concentrations of $A$. indica extracts. Values are expressed as mean \pm SEM $(n=9)$. Statistical analysis was carried out using one-way ANOVA followed by $t$ test. * Statistically significant between extract concentrations vs. the untreated control at ${ }^{*} p<0.05$ 
$(p>0.05)$ DPPH scavenging activity as compared to ascorbic acid, while root extract had significantly lower $(p<0.05)$ DPPH scavenging activity as compared to ascorbic acid. Referring to $\mathrm{IC}_{50}$ values, Table 1 also confirms higher antioxidant activity against DPPH for aerial parts extract compared to root extract.

\section{Cell viability (MTT assay) of $A$. indica extracts on human skin fibroblast cells (HSF 1189)}

Figure 2 illustrates fibroblasts viability after $24 \mathrm{~h}$ of treatment according to MTT assay. Both aerial parts and root extracts showed low cytotoxicity towards fibroblast cells with $753 \mu \mathrm{g} / \mathrm{mL} \mathrm{LD}_{50}$ for aerial parts and undetected $\mathrm{LD}_{50}$ for root extract. Figure 2 also confirms that at $100 \mu \mathrm{g} / \mathrm{mL}$ and $1 \mu \mathrm{g} / \mathrm{mL}$ aerial parts extract significantly $(p<0.05)$ induces fibroblasts proliferation up to $134 \%$ and $107.9 \%$ respectively.

\section{Wound scratch assay of $A$. indica extracts on human skin fibroblast cells (HSF 1189)}

To assess the in vitro wound healing effect of $A$. indica, we monitored fibroblasts migration concerning the closure of the uncovered scratched area. Figure 3 illustrates the enclosure process under stimulation of $A$. indica areal parts and root extracts.

Figure 4A confirms that low concentrations of aerial parts extract highly promote closure of the scratched area up to $70 \%$; however, $1 \mu \mathrm{g} / \mathrm{mL}$ significantly $(p<0.111)$ increases the closure up to $75 \%$ compared to the untreated control, which made only $59 \%$ closure after $48 \mathrm{~h}$ of the study. On the other hand, higher concentrations showed a low closure percentage with only $48 \%$ (less than untreated control) for $100 \mu \mathrm{g} / \mathrm{mL}$, while cells in $1000 \mu \mathrm{g} / \mathrm{mL}$ died after $6 \mathrm{~h}$ of treatment. Similarly, Fig. 4B confirms that low concentrations of root extract promote closure of the scratched area up to $70 \%$. While $1000 \mu \mathrm{g} /$ $\mathrm{mL}$ showed lower closure as compared to untreated control with only $48 \%$.

\section{Discussion}

We found that ethanolic extracts of both aerial parts and root have high antioxidant activity, support fibroblasts viability, and accelerate fibroblasts migration. These mechanisms target multiple phases of the dynamic wound healing process, making them, along with the previously reported anti-inflammatory and antimicrobial

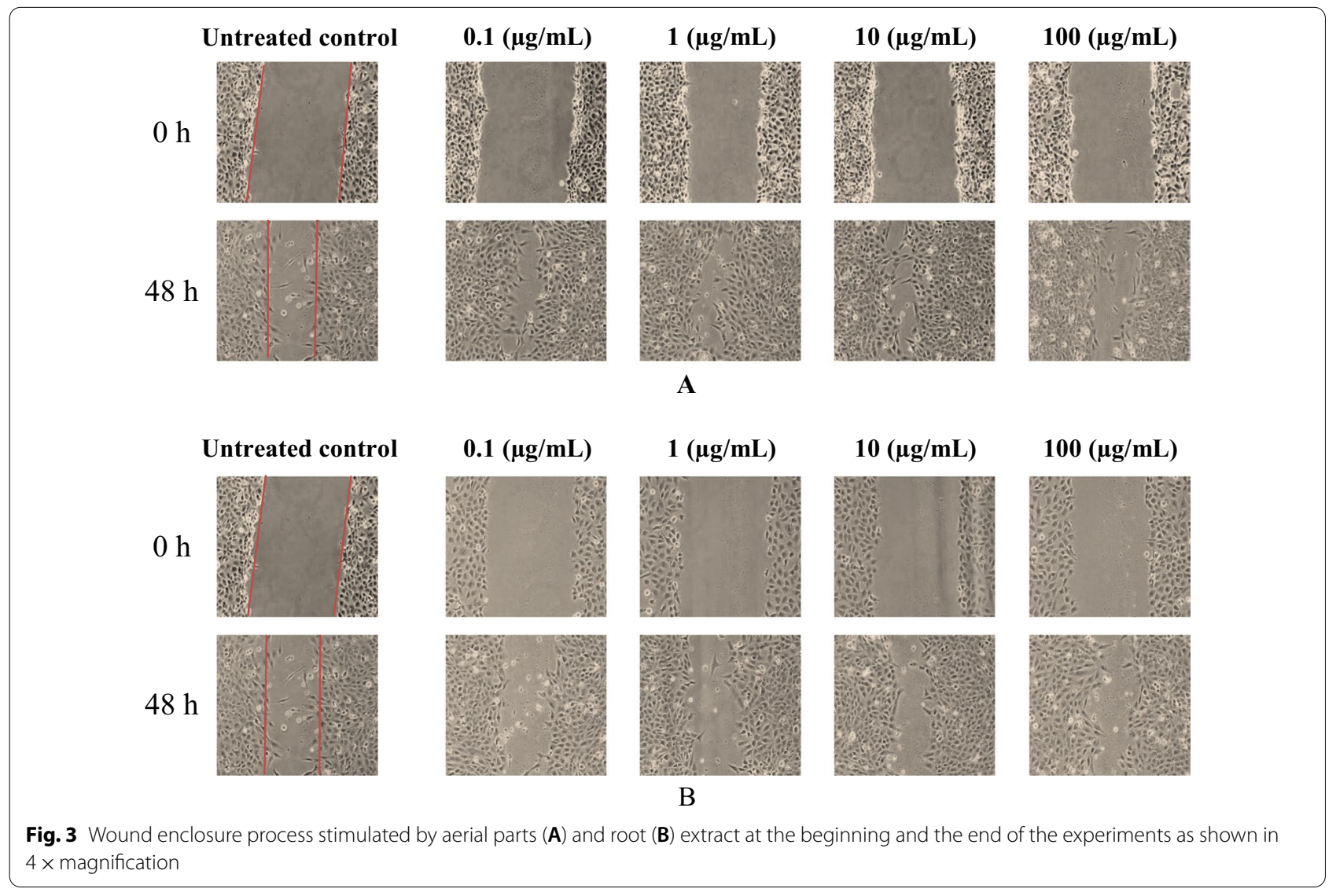



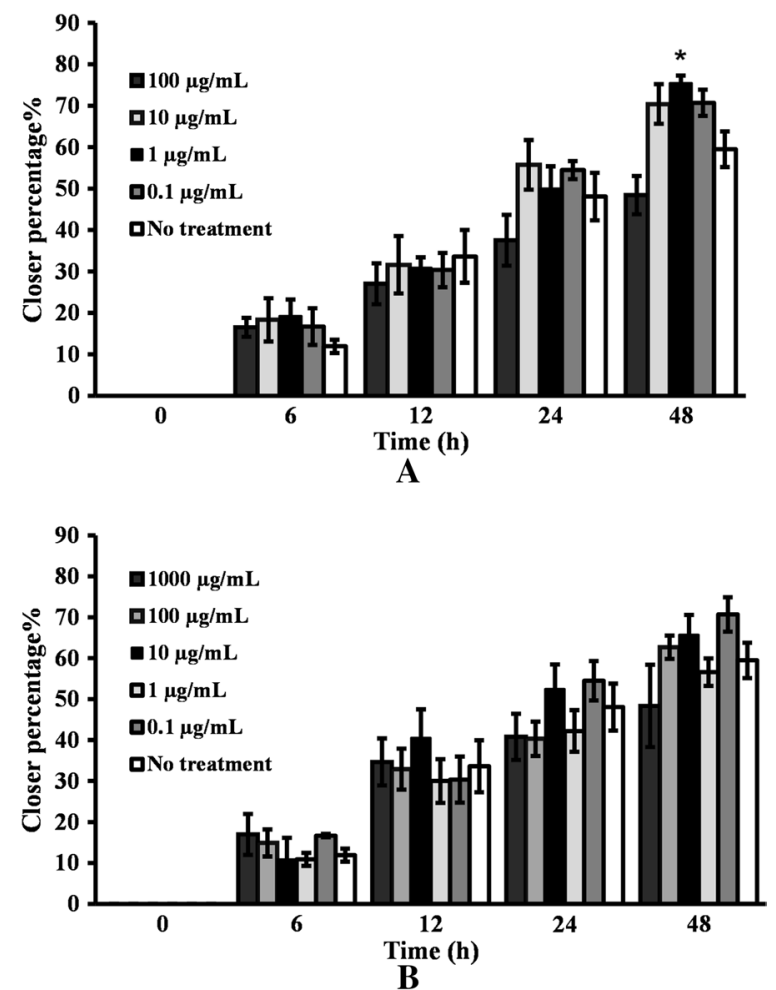

Fig. 4 Closure percentage of wound area with different concentrations of $A$. indica aerial parts $(\mathbf{A})$ and root $(\mathbf{B})$ extracts. Data represent mean \pm SEM $(n=4)$. Statistical analysis was carried out using one-way ANOVA followed by $t$ test. *Statistically significant between extract concentrations vs. the untreated control in each time interval at ${ }^{*} p<0.111$

activities, the main factors to manage wounds by $A$. indica.

Many studies proved the beneficial effect of plantbased antioxidants on the wound repair process. San Miguel et al. [26] showed in their study that antioxidants lower inflammatory markers and facilitate wound healing by promoting fibroblast migration. Additionally, applying plant-based antioxidants to wound area accelerates the wound healing process because they scavenge free radicals that damage live tissues and delay the wound healing process [27, 28].

Previous studies reported the antioxidant activity of different $A$. indica aerial parts extracts (methanol, hexane, acetone, and chloroform); the methanolic extract showed the highest antioxidant activity [29, 30]. Our study reported the antioxidants activity of the aerial parts and root ethanolic extracts (Fig. 1 and Table 1). Dineshkumar et al. [7] and Nahrstedt et al. [6] attribute the antioxidant activity of aerial parts to the presence of antioxidant entities such as acalyphamide and acalyphine. However, further investigation is needed to explain the low antioxidant activity of the root compared to aerial parts. We need to identify whether the low antioxidant activity of the root extract is because aerial parts are richer in phytochemicals-especially phenolic compounds-or other compounds are responsible for the antioxidant activity of the root extract $[6,7]$.

Upon skin injury, cells respond to the disruption in cell-cell contact by releasing cytokines, growth factors, and chemotactants, which trigger different types of cells [31]. Fibroblasts start to proliferate and migrate when triggered, promoting the newly formed connective tissue to contract [32, 33]. Figures 2, 3, 4 support our hypothesis of using-both aerial parts and root $-A$. indica ethanolic extracts to manage wounds by facilitating fibroblasts viability and migration. We noticed that the extract of the aerial parts showed a significant closure percentage compared to the root extract after $48 \mathrm{~h}$ of study, and aerial parts extract showed higher DPPH scavenging activity compared to root extract. On the other hand, while only aerial parts extract promoted fibroblasts proliferation, both aerial parts and root extracts showed no cytotoxicity on fibroblasts.

\section{Conclusions}

In this study, we found that $A$. indica boosts the healing process not only by-previously reported-anti-inflammatory, antioxidant, and antimicrobial activities but also by stimulating fibroblasts viability and migration. Thus, we can use fibroblasts to explore further the healing mechanisms attributed to $A$. indica. We also associate the high healing properties for the aerial parts with the high antioxidant activity compared to the root, which has low antioxidant activity; thus, low healing properties.

\section{Abbreviations}

DPPH: 2,2-Diphenyl-1-picrylhydrazyl; DMSO: Dimethyl sulfoxide; DMEM: Dulbecco's modified Eagle's medium; FBS: Fetal bovine serum; MTT: 3-(4,5-Dimethylthiazol-2-yl)-2,5-diphenyltetrazolium bromide; PBS: Phosphate buffered saline; ABS: Bovine serum albumin; Pen Strep: Penicillin and streptomycin; HSF 1189: Human skin fibroblast cell line.

\section{Acknowledgements}

The authors acknowledge Faculty of Science, Universiti Teknologi Malaysia for the laboratory equipment. The authors would like to thank Dr. Nor Syahiran Zahidin for providing the plant and would also like to thank Institute of Bioscience, Universiti Putra Malaysia Selangor, Malaysia and Dr. Mohd Firdaus Ismail for the plant identification and authorisation.

\section{Plant authentication \\ The plant species were scientifically authorised in the Institute of Biosci- ence, Universiti Putra Malaysia (Voucher No. SK 3146/17).}

\section{Authors' contributions}

Al investigated and drafted the work. MAH done substantial contribution in analysis of the data. RA edited and revised the manuscript. AS made substantial contribution in acquisition of raw material and revision of the study. RZ conceptualised, administrated the project, and received funding. All authors have read and approved the manuscript. 


\section{Funding}

Funded by Universiti Teknologi Malaysia (Research Grant Q10H84).

\section{Availability of data and materials}

All data and material are available on request.

\section{Declarations}

\section{Ethics approval and consent to participate}

Not applicable.

\section{Consent for publication}

Not applicable.

\section{Competing interests}

The authors declare that they have no competing interests.

\section{Author details}

${ }^{1}$ Department of Biosciences, Faculty of Science, Universiti Teknologi Malaysia, 81310 Skudai, Johor, Malaysia. ${ }^{2}$ School of Chemical and Energy Engineering, Faculty of Engineering, Universiti Teknologi Malaysia, 81310 Skudai, Johor, Malaysia.

Received: 30 November 2020 Accepted: 25 August 2021

Published online: 31 August 2021

\section{References}

1. Fazil M, Nikhat S (2020) Topical medicines for wound healing: a systematic review of Unani literature with recent advances. J Ethnopharmacol 257:112878. https://doi.org/10.1016/j.jep.2020.112878

2. Maver T, Maver U, Stana Kleinschek K, Smrke DM, Kreft S (2015) A review of herbal medicines in wound healing. Int J Dermatol 54:740-751. https://doi. org/10.1111/ijd.12766

3. Winter GD, Scales JT (1963) Effect of air drying and dressings on the surface of a wound. Nature 197:91-92

4. Houghton PJ, Hylands PJ, Mensah AY, Hensel A, Deters AM (2005) In vitro tests and ethnopharmacological investigations: wound healing as an example. J Ethnopharmacol 100:100-107. https://doi.org/10.1016/j.jep.2005.07.001

5. Upadhyay B, Roy S, Kumar A (2007) Traditional uses of medicinal plants among the rural communities of Churu district in the Thar Desert, India. J Ethnopharmacol 113:387-399. https://doi.org/10.1016/j.jep.2007.06.010

6. Nahrstedt A, Hungeling M, Petereit F (2006) Flavonoids from Acalypha indica. Fitoterapia 77:484-486. https://doi.org/10.1016/j.fitote.2006.04.007

7. Dineshkumar B, Vigneshkumar P, Bhuvaneshwaran SP, Mitra A (2010) Phytopharmacology of Acalypha indica: a review. Int J Biosci 1:27-32

8. Nunes CDR, Barreto Arantes M, Menezes de Faria Pereira S, Leandro da Cruz L, de Souza Passos M, Pereira de Moraes L, Vieira IJC, Barros de Oliveira D (2020) Plants as sources of anti-inflammatory agents. Molecules 25:3726-3748. https://doi.org/10.3390/molecules25163726

9. Zahidin NS, Saidin S, Zulkifl MR, Idayu Muhamed I, Ya'akob H, Nur H (2017) A review of Acalypha indica L. (Euphorbiaceae) as traditional medicinal plant and its therapeutic potential. J Ethnopharmacol 207:146-173. https://doi.org/10. 1016/j.jep.2017.06.019

10. Reddy JS, Rao PR, Reddy MS (2002) Wound healing effects of Heliotropium indicum, Plumbago zeylanicum and Acalypha indica in rats. J Ethnopharmacol 79:249-251. https://doi.org/10.1016/S0378-8741(01)00388-9

11. Ganeshkumar M, Ponrasu T, Krithika R, Iyappan K, Gayathri VS, Suguna L (2012) Topical application of Acalypha indica accelerates rat cutaneous wound healing by up-regulating the expression of Type I and III collagen. J Ethnopharmacol 142:14-22. https://doi.org/10.1016/j.jep.2012.04.005

12. Jenifer P, Kalachaveedu M, Viswanathan A, Gnanamani Mubeena A (2018) Fabricated approach for an effective wound dressing material based on a natural gum impregnated with Acalypha indica extract. J Bioact Compat Polym 33:612-628. https://doi.org/10.1177/0883911518801046

13. Laut M, Ndaong NA, Utami T (2019) Cutaneous wound healing activity of herbal ointment containing the leaf extract of Acalypha indica L.on mice (Mus musculus). J Phys Conf Ser 1146:012025. https://doi.org/10.1088/1742-6596/ 1146/1/012025
14. Boomi P, Ganesan R, Prabu Poorani G, Jegatheeswaran S, Balakumar C, Gurumallesh Prabu H, Anand K, Marimuthu Prabhu N, Jeyakanthan J, Saravanan M (2020) Phyto-engineered gold nanoparticles (AuNPs) with potential antibacterial, antioxidant, and wound healing activities under in vitro and in vivo conditions. Int J Nanomed 15:7553-7568. https://doi.org/10.2147/IJN. S257499

15. Nirmal N, Praba GO, Velmurugan D (2008) Modeling studies on phospholipase A2-inhibitor complexes. Indian J Biochem Biophys 45:256-262

16. Rahman MA, Bachar SC, Rahmatullah M (2010) Analgesic and anti inflammatory activity of methanolic extract of Acalypha indica Linn. Pak J Pharm Sci 23:256-258

17. Hussain AZ, Ignatius A (2010) GC-MS analysis and antimicrobial activity of Acalypha indica Linn. Asian J Chem 22:3591-3595

18. Darby IA, Laverdet B, Bonté F, Desmoulière A (2014) Fibroblasts and myofibroblasts in wound healing. Clin Cosmet Investig Dermatol 7:301-311. https:// doi.org/10.2147/CCID.S50046

19. Gauthier C, Griffin G (2005) Using animals in research, testing and teaching Rev Sci Tech 24:735-745. https://doi.org/10.20506/rst.24.2.1601

20. Brighente IMC, Dias M, Verdi LG, Pizzolatti MG (2007) Antioxidant activity and total phenolic content of some Brazilian species. Pharm Biol 45:156-161. https://doi.org/10.1080/13880200601113131

21. Munro B, Vuong QV, Chalmers AC, Goldsmith CD, Bowyer MC, Scarlett CJ (2015) Phytochemical, antioxidant and anti-cancer properties of Euphorbia tirucalli methanolic and aqueous extracts. Antioxidants 4:647-661. https:// doi.org/10.3390/antiox4040647

22. Jamaludin R, Mohd N, Safazliana R, Sulong R, Yaakob H (2021) Andrographis paniculata-loaded niosome for wound healing application: characterisation and in vivo analyses. J Drug Deliv Sci Technol 63:102427. https://doi.org/10. 1016/j.jddst.2021.102427

23. Rehana D, Mahendiran D, Kumar RS, Rahiman AK (2017) Evaluation of antioxidant and anticancer activity of copper oxide nanoparticles synthesized using medicinally important plant extracts. Biomed Pharmacother 89:1067-1077. https://doi.org/10.1016/j.biopha.2017.02.101

24. Liang CC, Park AY, Guan JL (2007) In vitro scratch assay: a convenient and inexpensive method for analysis of cell migration in vitro. Nat Protoc 2:329-333. https://doi.org/10.1038/nprot.2007.30

25. Jonkman JEN, Cathcart JA, Xu F, Bartolini ME, Amon JE, Stevens KM, Colarusso P (2015) An introduction to the wound healing assay using live-cell microscopy. Cell Adh Migr 8:440-451. https://doi.org/10.4161/cam.36224

26. San Miguel SM, Opperman LA, Allen EP, Zielinski J, Svoboda KK (2010) Antioxidant compounds increased wound healing migration via Rac-GTP activation in nicotine-treated human gingival and PDL fibroblasts. J Periodontol 81:1675-1690

27. Rasik AM, Shukla A (2000) Antioxidant status in delayed healing type of wounds. Int J Exp Pathol 81:257-263. https://doi.org/10.1046/j.1365-2613. 2000.00158.x

28. Barku WYA (2019) Wound healing: contributions from plant secondary metabolite antioxidants. In: Wound healing-current perspectives. IntechOpen. https://doi.org/10.5772/intechopen.81208

29. Sanseera D, Niwatananun W, Liawruangrath B, Liawruangrath S, Baramee A Trisuwan K, Pyne SG (2012) Antioxidant and anticancer activities from aerial parts of Acalypha indica Linn. Chiang Mai Univ J Nat Sci 11:157-168

30. Evangeline S, Sundaram V, Manian RP, Kulanthaivelu K, Balasundaram S (2015) Antioxidant, antibacterial and anti-inflammatory activity of Acalypha indica and Terminalia chebula: An in-vitro analysis. Res J Pharm Biol Chem Sci 6:388-396

31. Eming SA, Martin P, Tomic-canic M (2014) Wound repair and regeneration: mechanisms, signaling, and translation. Sci Transl Med 6:1-36. https://doi. org/10.1126/scitranslmed.3009337

32. Montesano R, Orci L (1988) Transforming growth factor beta stimulates collagen-matrix contraction by fibroblasts: implications for wound healing. Proc Natl Acad Sci U S A 85:4894-4897. https://doi.org/10.1073/pnas.85.13. 4894

33. Yamauchi M, Gibbons DL, Zong C, Fradette JJ (2020) Fibroblast heterogeneity and its impact on extracellular matrix and immune landscape remodeling in cancer. Matrix Biol 91-92:8-18. https://doi.org/10.1016/j.matbio.2020.05.001

\section{Publisher's Note}

Springer Nature remains neutral with regard to jurisdictional claims in published maps and institutional affiliations. 